University of Wollongong

Research Online

Faculty of Engineering and Information

Faculty of Engineering and Information

Sciences - Papers: Part A

Sciences

$1-1-2014$

Removal of polycyclic musks by anaerobic membrane bioreactor: biodegradation, biosorption, and enantioselectivity

Lili Wang

University of New South Wales

Kaushalya C. Wijekoon

University of Wollongong, kcw998@uowmail.edu.au

Long D. Nghiem

University of Wollongong, longn@uow.edu.au

Stuart J. Khan

University of New South Wales, s.khan@unsw.edu.au

Follow this and additional works at: https://ro.uow.edu.au/eispapers

Part of the Engineering Commons, and the Science and Technology Studies Commons

Research Online is the open access institutional repository for the University of Wollongong. For further information contact the UOW Library: research-pubs@uow.edu.au 


\title{
Removal of polycyclic musks by anaerobic membrane bioreactor: biodegradation, biosorption, and enantioselectivity
}

\begin{abstract}
This study aims to investigate the performance of anaerobic membrane bioreactor (AnMBR) for removing five polycyclic musks (PCMs), which are common active ingredients of personal care and household cleaning products. A laboratory scale AnMBR system was used in this investigation. Concentrations of the PCMs in both the liquid and biosolids phase were measured to conduct a mass balance analysis and elucidate their fate during AnMBR treatment. The AnMBR was effective for removing PCMs from the aqueous phase by a combination of biotransformation and sorption onto the biosolids. However, biotransformation was observed to be the dominant removal mechanism for all five PCMs. Enantioselective analysis of the PCMs in influent, effluent and biomass samples indicated that there was negligible enantioselectivity in the removal of these PCMs. Accordingly, all enantiomers of these PCMs can be expected to be removed by AnMBR with similar efficiency.

\section{Disciplines \\ Engineering | Science and Technology Studies}

\section{Publication Details}

Wang, L., Wijekoon, K. C., Nghiem, L. D. \& Khan, S. J. (2014). Removal of polycyclic musks by anaerobic membrane bioreactor: biodegradation, biosorption, and enantioselectivity. Chemosphere, 117 722-729.
\end{abstract}




\title{
1 Removal of Polycyclic Musks by Anaerobic Membrane Bioreactor:
}

2 Biodegradation, biosorption, and enantioselectivity

3 LiliWang ${ }^{a}$, Kaushalya C. Wijekoon ${ }^{b}$, Long D. Nghiem ${ }^{b}$, Stuart J. Khan ${ }^{a, *}$

$4 \quad{ }^{\mathrm{a}}$ UNSW Water Research Centre, School of Civil and Environmental Engineering, University of New

5 South Wales, Sydney, NSW 2052, Australia.

6 b ${ }^{\mathrm{b}}$ Strategic Water Infrastructure Laboratory, School of Civil Mining and Environmental Engineering,

7 University of Wollongong, Wollongong, NSW 2522, Australia

*Corresponding Author: Telephone: +61 2 93855070, Fax: +61 2 93138624, Email:

s.khan@unsw.edu.au

\begin{abstract}
This study aims to investigate the performance of anaerobic membrane bioreactor (AnMBR) for removing five polycyclic musks (PCMs), which are common active ingredients of personal care and household cleaning products. A laboratory scale AnMBR system was used in this investigation. Concentrations of the PCMs in both the liquid and biosolids phase were measured to conduct a mass balance analysis and elucidate their fate during AnMBR treatment. The AnMBR was effective for removing PCMs from the aqueous phase by a combination of biotransformation and sorption onto the biosolids. However, biotransformation was observed to be the dominant removal mechanism for all five PCMs. Enantioselective analysis of the PCMs in influent, effluent and biomass samples indicated that there was negligible enantioselectivity in the removal of these PCMs. Accordingly, all enantiomers of these PCMs can be expected to be removed by AnMBR with similar efficiency.
\end{abstract}

Keywords: Anaerobic membrane bioreactor (AnMBR), polycyclic musks (PCMs), biodegradation, enantioselectivity, sorption.

\section{Introduction}

Reclaimed municipal effluent is an increasingly important water resource used in many countries for a diverse range of applications including agricultural irrigation, industrial processes, non-potable usage and even to supplement potable water supplies. As a consequence, there has been an increasing attention to the elimination of trace organic chemicals (TrOCs) during the wastewater treatment and reclamation processes. Conventional wastewater treatment processes were not specifically developed for removing TrOCs (Le-Minh et al., 2010b; Rivera-Utrilla et al., 2013). Thus, the removal of some TrOCs can be quite low or highly variable. In recent years, membrane bioreactors (MBRs) have been shown to improve the removal of refractory trace chemicals as a consequence of extended biosolids retention times and high biomass concentrations (Alturki et al., 2010; Le-Minh et al., 2010a; Le-Minh 
et al., 2010b). Many studies have shown the effective removal of TrOCs including pharmaceuticals and personal care products (PPCPs), pesticides, and endocrine disrupting chemicals by MBRs (Coleman et al., 2009; Nghiem et al., 2009; Tadkaew et al., 2011; Trinh et al., 2012). In particular, MBRs have been shown to achieve improved removal of some contaminants, which have otherwise been considered to be relatively persistent and recalcitrant compounds during treatment (Clara et al., 2005; De Wever et al., 2007; Radjenovic et al., 2009; Sipma et al., 2010; Tambosi et al., 2010).

In addition to the more established aerobic MBR systems, there is a growing interest in of the deployment of anaerobic MBR (AnMBR) systems for municipal wastewater treatment (Lew et al., 2009). Compared to aerobic MBR, AnMBR can be much more energy efficient but can also maintain a high effluent quality suitable for environmental discharge and water reuse. Other advantages of AnMBRs include the reduction in chemical consumption and sludge production. In addition, AnMBR can convert the organic content in wastewater to biogas, which is a renewable fuel (Visvanathan and Abeynayaka, 2012).

Several studies have previously been conducted to investigate the removal efficiencies of micropollutants using AnMBRs (Xu et al., 2008; Monsalvo et al., 2014). Most of these have focused on high strength organic industrial wastewater such as alcohol-distillery and brewery wastewater (Choo and Lee, 1998; Ince et al., 1998). More recently, there has been a focus on the use of AnMBRs for treating municipal wastewater at centralised (Saddoud et al., 2007; Baek et al., 2010; MartinezSosa et al., 2011) and decentralised (Wen et al., 1999; Lew et al., 2009) facilities. The potential to apply AnMBR for municipal wastewater treatment is the development in sewer mining, in which, clean water is extracted from the sewer at source (Butler and MacCormick, 1996; Xie et al., 2013). The remaining wastewater is of much higher wastewater strength and is suitable for anaerobic treatment. However, while information about the removal of TrOCs by AnMBRs is still limited, little is known about the fate of polycyclic musks (PCMs) during AnMBR treatment. PCMs are commonly used ingredients in personal care and household cleaning products. They have been reported to be resistant to biodegradation under aerobic conditions, which has led to their detection at high concentrations in wastewater treatment plant effluents and in effluent impacted water bodies (Ricking et al., 2003; Yang and Metcalfe, 2006; Clara et al., 2011; Wang and Khan, 2014).

Most PCMs are chiral chemicals. For examples, tonalide (AHTN), phantolide (AHDI), and cashmeran (DPMI) have one chiral centre. Some PCMs such as galaxolide (HHCB) and traseolide (ATII) have two chiral centres. As such, AHTN, AHDI and DPMI may occur in two enantiomeric forms, while HHCB and ATII have four stereoisomers. However, commercial formulations of ATII tend to produce only the 'trans' configurations (Gatermann et al., 2002). Consistent with this, only two enantiomers of ATII were detected in analytical standards and in environmental samples. Our previous research has shown that these chemicals are used and occur in municipal wastewater as an 
even composition of each of the possible enantiomers (Wang and Khan, 2014). However, it is known that the enantiomeric fractions (EF) of some chiral chemicals may be changed during biological wastewater treatment processes (Hashim and Khan, 2011; Hashim et al., 2011). Accordingly, this investigation was undertaken using an enantiospecific analytical method to enable observation of any changes in EF during AnMBR treatment.

\section{Materials and Methods}

\subsection{Materials}

Five chiral PCMs were investigated in this study. Their molecular structures are shown in Table 1 and the chiral centre is marked by an asterisk. Analytical standards of synthetic PCMs including HHCB, AHTN, DPMI, AHDI and ATII, as well as isotope-labelled internal standard AHTN-d3 were purchased from Dr.Ehrenstorfer GmbH (Augsburg, Germany). Ethyl acetate (anhydrous spectroscopy grade) was purchased from Sigma Aldrich, Australia. HPLC grade methanol was purchased from Ajax Finechem (Taren Point, NSW, Australia). Kimble culture tubes (13mm I.D. $\times 100 \mathrm{~mm}$ ) and a Thermo Speedvac ${ }^{\mathrm{TM}}$ concentrator (Model No. SPD121P) were purchased from Biolab (Clayton, Vic, Australia). Oasis Hydrophilic-lipophilic balance (HLB) solid phase extraction cartridges (6cc, 500mg) were purchased from Waters (Rydalmere, NSW, Australia). Whatman Grade 1 filter papers $(0.75 \mu \mathrm{m}$ particle retention) were purchased from Millipore, Australia. Ultrapure water was produced by a Driec- $\mathrm{Q}^{\mathrm{TM}}$ filtering system, which is also from Millipore.

Table 1: Chemical name, common trade names and molecular structures of five PCMs

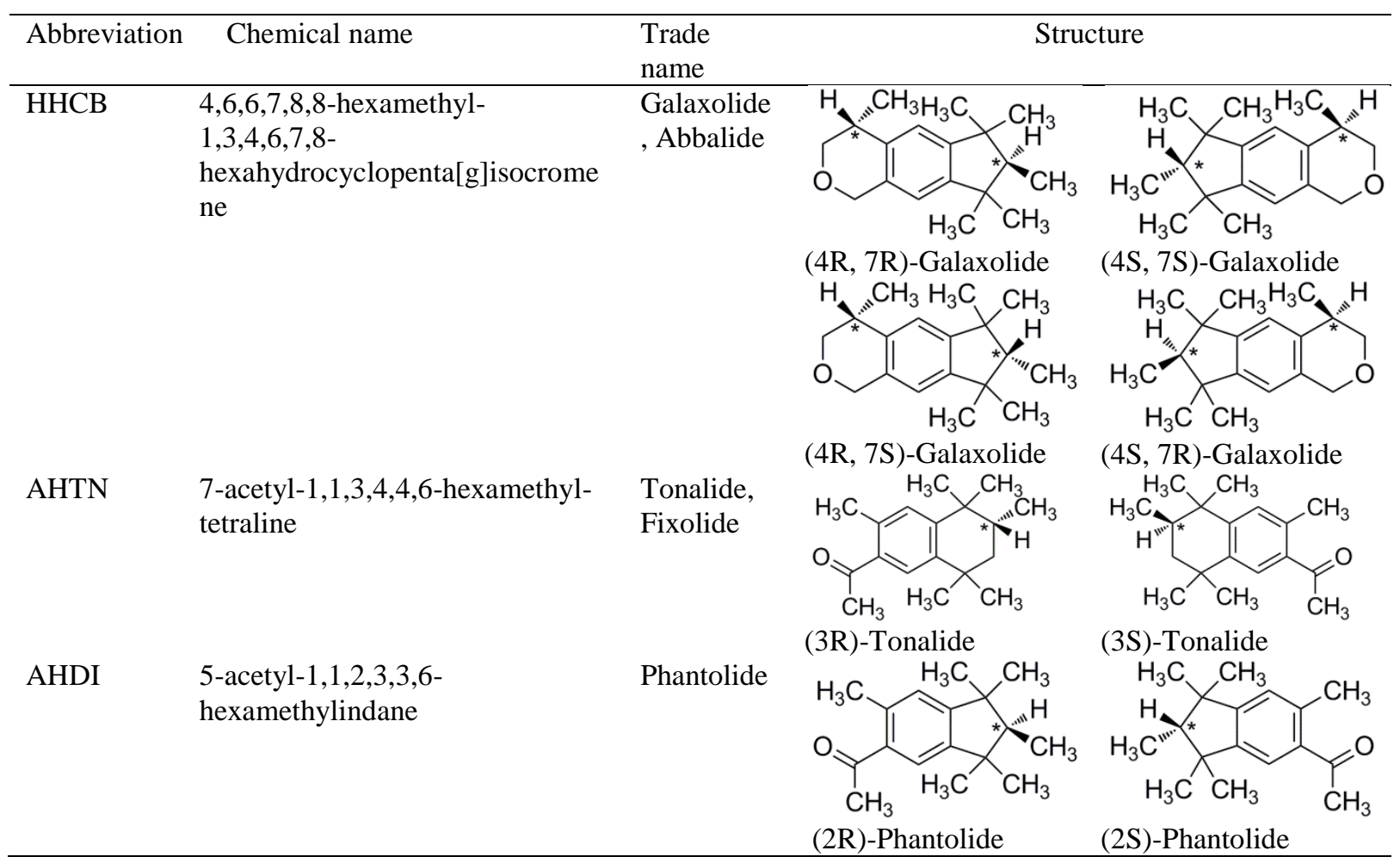




\begin{tabular}{llll}
\hline ATII -acetyl-1,1,2,6-tetramethyl-3- \\
isopropylindane
\end{tabular}

87

A laboratory scale AnMBR system was used to assess the fate of PCMs. This system consists of a 10 L steel feed container, $30 \mathrm{~L}$ stainless steel reactor chamber, four pumps including an feed pump, a sludge circulation pump, an retentate recirculation pump and a permeate suction pump, a temperature control unit, and an external ceramic membrane filtration unit (see Figure 1). A singular tubular ceramic membrane module with a nominal pore size of $0.1 \mu \mathrm{m}$ and an effective membrane surface area of $0.09 \mathrm{~m}^{2}$ was used for these experiments.

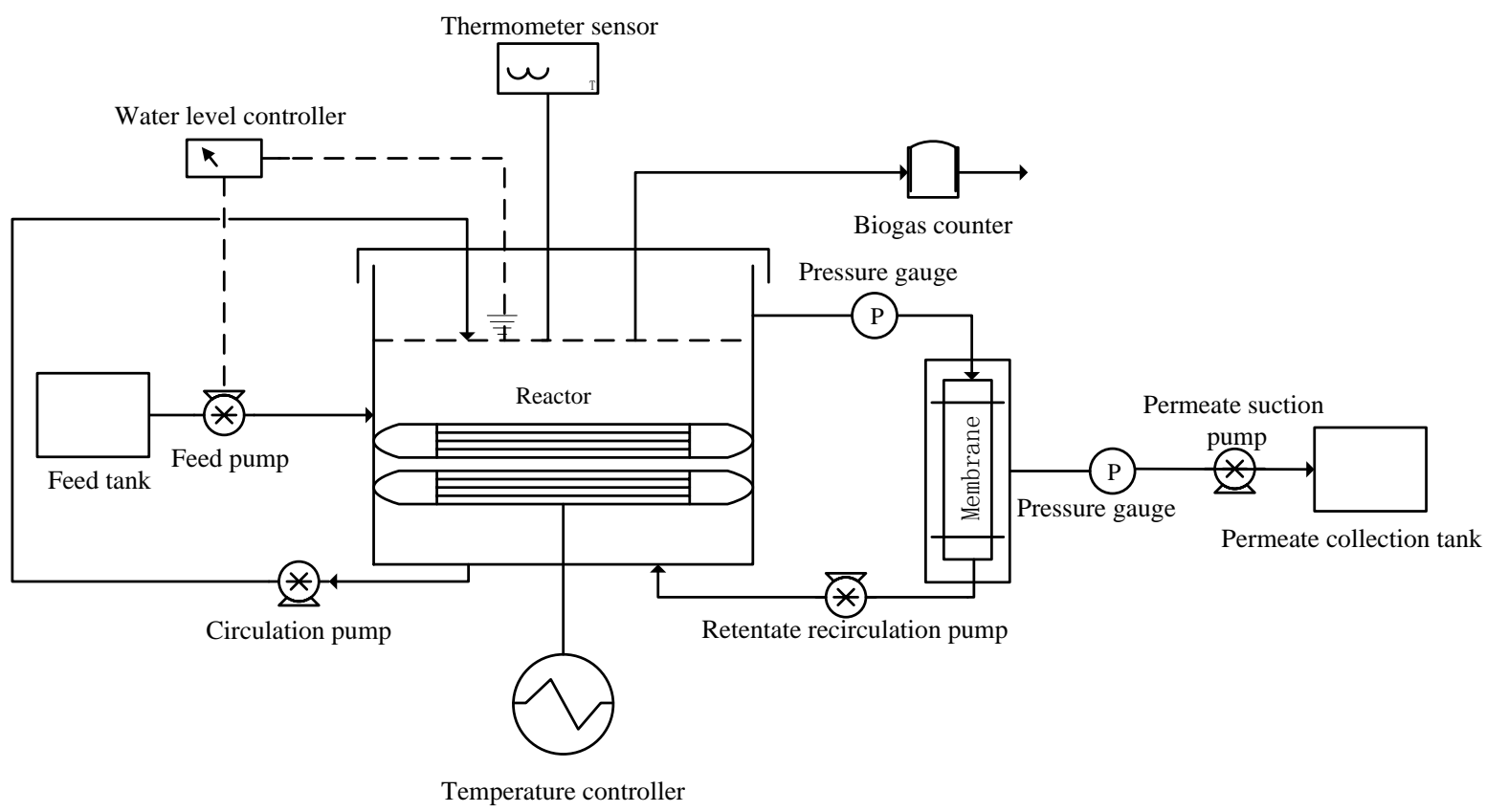

Figure 1: Diagram of the laboratory scale AnMBR

97 Peristaltic pumps (Masterflex L/S, USA) were used for influent feed, recirculation, and effluent extraction. The feed pump was connected to a water level controller to maintain the working volume 
in the reactor at $20 \mathrm{~L}$. The retentate recirculation pump was operated in a $15 \mathrm{~min}$ on and $1 \mathrm{~min}$ off cycle to provide relaxation time to the membrane module for reducing the fouling. A peristaltic suction pump was used to drive MBR permeate across the membrane. An industrial grade peristaltic hose pump (ProMinent, Australia) with higher working power was used for circulating sludge. The temperature controller (Thermo Electron Corporation, Australia) was used to maintain the reactor at $35{ }^{\circ} \mathrm{C}$. The effluent flow rate was adjusted to be the same as the influent flow rate to maintain a constant reactor volume. Chemical cleaning of the ceramic membrane was conducted once per month.

\subsection{AnMBR experimental protocol}

Synthetic wastewater was used in this study to facilitate precise compositional control and to avoid pathogen exposure risks to personnel. The synthetic wastewater solution was prepared according to the composition shown in Table 2 based on a previous publication (Hashim et al., 2011). Concentrated synthetic wastewater was stored in a refrigerator at $4{ }^{\circ} \mathrm{C}$. The reactor was seeded with sludge from an anaerobic digester of the Wollongong Sewage Treatment Plant (NSW, Australia). $\mathrm{NaHCO}_{3}$ was used as buffer during acclimatisation to stabilise the reactor $\mathrm{pH}$ of $7 \pm 0.1$. The $\mathrm{pH}$ of the mixed liquor was monitored using an Orion 4 Star Plus portable $\mathrm{pH} /$ conductivity meter (Thermo Scientific, Waltham, MA).

Table 2: Composition of AnMBR synthetic wastewater

\begin{tabular}{|l|l|l|}
\hline Chemical & Chemical formula & Concentration $\left(\mathbf{m g ~ L}^{-1}\right)$ \\
\hline Glucose & $\mathrm{C}_{6} \mathrm{H}_{12} \mathrm{O}_{6}$ & 4000 \\
\hline Peptone & - & 750 \\
\hline Potassium dihydrogen phosphate & $\mathrm{KH}_{2} \mathrm{PO}_{4}$ & 175 \\
\hline Magnesium sulphate & $\mathrm{MgSO}_{4}$ & 175 \\
\hline Sodium acetate & $\mathrm{CH}_{3} \mathrm{COONa}$ & 2250 \\
\hline Urea & $\mathrm{CO}\left(\mathrm{NH}_{2}\right)_{2}$ & 135 \\
\hline FeCl $2.4 \mathrm{H}_{2} \mathrm{O}$ & $\mathrm{FeCl}_{2} \cdot 4 \mathrm{H}_{2} \mathrm{O}$ & 112 \\
\hline Nickel chloride & $\mathrm{NiCl}_{2} \cdot 6 \mathrm{H}_{2} \mathrm{O}$ & 21 \\
\hline Cobalt chloride & $\mathrm{CoCl}_{2} \cdot 6 \mathrm{H}_{2} \mathrm{O}$ & 13 \\
\hline Ammonium molybdate & $\left(\mathrm{NH}_{4}\right)_{6} \mathrm{Mo}_{7} \mathrm{O}_{24} \cdot 4 \mathrm{H}_{2} \mathrm{O}$ & 8 \\
\hline
\end{tabular}

After seeding, an initial system start-up and stabilisation process was undertaken for approximately 40 days. Following this period, a small quantity of biomass was regularly wasted from the reactor to establish and maintain a solids retention time (SRT) of approximately 150 days. The mixed liquor suspended solids (MLSS) concentration in the reactor was maintained at $10 \mathrm{~g} \mathrm{~L}^{-1}$. The hydraulic retention time was set at 4 days, corresponding to permeate flux of $5 \mathrm{~L} \mathrm{~d}^{-1}\left(2.36 \mathrm{~L} \mathrm{~m}^{-2} \mathrm{~h}^{-1}\right)$. The reactor 
temperature was kept constant at $35.0 \pm 0.1{ }^{\circ} \mathrm{C}$. Performance of the system with regard to basic water quality parameters was then monitored for assessment of the stability of the system. The measured parameters included total organic carbon (TOC) removal, total nitrogen (TN) removal, chemical oxygen demand (COD) removal and concentration of methane in biogas. TOC and TN were analysed using a TOC/TN-VCSH analyser (Shimadzu, Japan). COD was analysed using the dichromate method according to Standard Methods for the Examination of Water and Wastewater (Eugene W. Rice, 2012). Biogas composition was measured using a portable biogas analyser (Biogass 5000, Geotech, UK) following a protocol described elsewhere (Nghiem et al., 2014).

Once stable TOC removal and biogas production had been achieved, all five PCMs $\left(10 \mathrm{mg} \mathrm{L}^{-1}\right.$ in ethyl acetate $1 \mathrm{~mL}$ ) was added to the feed solution to obtain a concentration of approximately $2 \mu \mathrm{g} \mathrm{L}^{-1}$ of each compound. The feed solution was kept in a stainless steel reservoir in an air-conditioned laboratory maintained at a temperature of $20 \pm 2{ }^{\circ} \mathrm{C}$. Following the introduction of PCMs to the reactor feed, a further stabilisation time of three times the HRT (a total of 12 days) was enacted, during which no samples were collected. After day 12, duplicate feed $(500 \mathrm{~mL})$, permeate $(500 \mathrm{~mL})$ and MLSS (250 mL) samples were collected once per week over four weeks. The four weekly sampling events were indicated by S1, S2, S3 and S4.

\subsection{Biomass sample extraction}

Biomass extraction was undertaken using an adaptation of a method previously reported for extracting sewage sludge samples (Ternes et al., 2005; Coleman et al., 2009). The mixed liquor samples from the anaerobic reactor were centrifuged and the wet solid biomass was then stored in a china container and frozen for at least $24 \mathrm{~h}$ at $-25{ }^{\circ} \mathrm{C}$. The frozen biomass samples were then freeze dried for $36 \mathrm{~h}$ using a ModulyoD freeze dryer (Thermo Electron Corporation, Australia). The freeze dried samples were then subjected to ultrasonic solvent extraction. Firstly, the freeze dried samples were finely grounded using mortar and pestle. Duplicate samples $(0.5 \mathrm{~g}$ for each) were weighted into $13 \mathrm{~mL}$ glass culture tubes. The internal standard AHTN-d3 $\left(50 \mu \mathrm{L}, 1 \mu \mathrm{g} \mathrm{mL} \mathrm{mL}^{-1}\right)$ was added to the glass tube. $5 \mathrm{~mL}$ ethyl acetate was then added and the solution was thoroughly mixed for 3 mins using a vortex mixer. Each sample was then ultrasonicated for $10 \mathrm{mins}$ at $40{ }^{\circ} \mathrm{C}$ (Unisonics, Australia). The samples were centrifuged at 3000rpm for 5 mins and the supernatant was collected into glass culture tubes. Ethyl acetate $(5 \mathrm{~mL})$ was added to the remaining biomass. The whole process of mixing, ultrasonic solvent extraction and centrifugation was repeated and the supernatant was mixed together with the supernatant from the first step. The combined supernatants were diluted with MiliQ water $(500 \mathrm{~mL})$ into glass bottles for solid phase extraction (SPE).To determine the recoveries of individual PCMs, $0.5 \mathrm{~g}$ freeze dried and finely grounded biomass were spiked with $50 \mathrm{ng}, 200 \mathrm{ng}$ and $1000 \mathrm{ng}$ of PCMs, together with $50 \mathrm{ng}$ of internal standard and then subjected to the method described above. The method recoveries are presented in Table 3. 


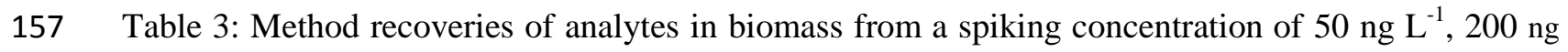
$158 \quad \mathrm{~L}^{-1}$ and $1000 \mathrm{ng} \mathrm{L}^{-1}, \mu( \pm \sigma) \%, \mathrm{n}=3$

\begin{tabular}{|l|l|l|l|}
\hline Analyte & $50 \mathrm{ng} \mathrm{L}^{-1}$ & $200 \mathrm{n} \mathrm{L}^{-1}$ & $1000 \mathrm{ng} \mathrm{L}^{-1}$ \\
\hline DPMI & $88( \pm 7)$ & $86( \pm 8)$ & $94( \pm 6)$ \\
\hline AHDI & $91( \pm 3)$ & $94( \pm 6)$ & $99( \pm 2)$ \\
\hline ATII & $97( \pm 4)$ & $96( \pm 4)$ & $97( \pm 5)$ \\
\hline AHTN & $96( \pm 7)$ & $95( \pm 4)$ & $102( \pm 6)$ \\
\hline HHCB & $93( \pm 3)$ & $93( \pm 7)$ & $101( \pm 4)$ \\
\hline
\end{tabular}

\subsection{Aqueous sample extraction}

Influent and permeate $(500 \mathrm{~mL})$ samples were filtered with a $0.75 \mu \mathrm{m}$ filter paper and then spiked with $50 \mathrm{ng}$ AHTN-d3. All the liquid samples were extracted using solid phase extraction by loading the samples onto the HLB cartridges conditioned with $5 \mathrm{~mL}$ ethyl acetate, $5 \mathrm{~mL}$ methanol and $5 \mathrm{~mL}$ MiliQ water. A full method validation is presented in previously published paper (Wang et al., 2013). After concentrating to $1 \mathrm{~mL}$, eluted samples were subjected to gas chromatography tandem mass spectrometry (GC-MS/MS) analysis.

\subsection{GC-MS/MS analysis}

Chromatographic separations of all the samples were performed on an Agilent 7890A gas chromatograph, equipped with a dual-column configuration of a chiral heptakis (2,3- di-O-methyl-6$O$-butyl dimethylsilyl)- $\beta$-cyclodextrin column coupled with a (non-chiral) HP-5MS column. Mass spectral detection was undertaken with an Agilent 7000B triple quadrupole mass spectrometer. Mass spectrometric ionisation was undertaken in electron ionisation (EI) mode with an EI voltage of $70 \mathrm{eV}$. Multiple reaction monitoring (MRM) was used to identified target PCMs. Detailed information about instrument, method and quality assurance and control is available elsewhere (Wang et al., 2013).

\subsection{Calculation of PCM mass balances and sorption coefficients $\mathrm{K}_{\mathrm{d}}$}

Mass balance calculation was conducted after 12 days of spiking PCMs until the system reached the equilibrium. Equilibrium was confirmed by the observation of steady-stage biosolids concentrations of PCMs after this time. The concentration of PCMs in influent $\left(\mathrm{C}_{\mathrm{in}}\left(\mathrm{ng} \mathrm{L^{-1 }}\right)\right)$, biomass $\left(\mathrm{C}_{\text {bio }}\left(\mathrm{ng} \mathrm{g}^{-1}\right)\right)$, and effluent $\left(\mathrm{C}_{\text {eff }}\left(\mathrm{ng} \mathrm{L}^{-1}\right)\right)$, MLSS $\left(\mathrm{C}_{\mathrm{MLSS}}=10 \mathrm{~g} \mathrm{~L}^{-1}\right)$, the volume of the MLSS taken out from the system every week $(750 \mathrm{~mL} /$ week) and the volume of influent and effluent every day $(5 \mathrm{~L})$ as well as the experimental time (21 days) were used to calculate the overall PCMs mass balances. The overall mass balance of each PCM during the experimental period was calculated for the whole system using the Eq.A.1: 
Influent load $(\mathrm{ng})=5 \mathrm{~L} \mathrm{day}^{-1} \times \mathrm{C}_{\mathrm{in}}\left(\mathrm{ng} \mathrm{L}^{-1}\right) \times 21$ days

Wasted biomass load $(\mathrm{ng})=\left(\mathrm{C}_{\mathrm{MLSS}}\left(\mathrm{g} \mathrm{L}^{-1}\right) \times(0.75 \mathrm{~L} /\right.$ week $\times 3$ weeks $\left.)\right) \times \mathrm{C}_{\text {bio }}\left(\mathrm{ng} \mathrm{g}^{-1}\right)$

Effluent load $(\mathrm{ng})=5 \mathrm{~L} \mathrm{day}^{-1} \times \mathrm{C}_{\mathrm{eff}}\left(\mathrm{ng} \mathrm{L}^{-1}\right) \times 21$ days

The calculation of sorption coefficients $\mathrm{K}_{\mathrm{d}}$ in the anaerobic reactor was performed according to (Joss et al., 2005). $\mathrm{K}_{\mathrm{d}}$ was defined as:

$\mathrm{K}_{\mathrm{d}}=\mathrm{C}_{\mathrm{s}} / \mathrm{C}_{\mathrm{w}}$

Where $\mathrm{K}_{\mathrm{d}}$ is the sorption coefficient $\left(\mathrm{L} \mathrm{KgSS}^{-1}\right), \mathrm{C}_{\mathrm{s}}$ is the sorbed concentration per amount of suspended solids ( $\mathrm{ug} \mathrm{KgSS}^{-1}$ ), $\mathrm{C}_{\mathrm{w}}$ is the measured concentration of effluent (ng L ${ }^{-1}$ ).

\section{Results and discussion}

3.1 Basic performance of the AnMBR system

After 40 days of system acclimatization, the AnMBR achieved a stable performance for TOC removal $(77 \pm 4 \%)$, TN removal $(77 \pm 3.5 \%)$ and COD removal $(84 \pm 2 \%)$. The biogas production and mixed liquor alkalinity were stable at $0.16 \mathrm{~L} \mathrm{CH} 4 / \mathrm{g}_{\mathrm{COD}}$ removed and $2100 \pm 124 \mathrm{mg} \mathrm{CaCO} / \mathrm{L}$ during the experimental period.

\subsection{Removal of PCMs by AnMBR}

The total concentrations of individual PCMs in influents and effluents are shown in Figure 2. The total concentrations of individual PCMs in influent were measured between 1.6-2.3 $\mu \mathrm{g} \mathrm{L}^{-1}$ for all five PCMs. The overall removal efficiency from influent to effluent was stable at over 95\% for each PCM. The concentration of PCMs in effluent ranged from $9.1 \mathrm{ng} \mathrm{L}^{-1}$ to $97 \mathrm{ng} \mathrm{L}^{-1}$. The performance of AnMBR for removing of trace organics has previously been reported to be strongly related to the properties of the chemicals (Monsalvo et al., 2014). Hydrophobic and easily degradable compounds typically show high removal efficiencies by sorption to biomass and biotransformation.

The removal efficiencies of PCMs by full scale and laboratory scale aerobic MBR are usually moderate $(50 \%)$ to high and sorption onto the biomass is expected to be the predominant mechanism of eliminating these compounds (Joss et al., 2005; Ternes et al., 2005; Kupper et al., 2006). Compared with aerobic MBRs, the performance of eliminating PCMs by this laboratory scale AnMBR is very good. The reason for the relatively high removal efficiency by the system may be attributed to the long HRT and SRT applied. The high sludge age achieved by the long SRT may facilitate an adaption of microorganisms responsible for less biodegradable PCMs. Previous investigations have also 
indicated that high sludge retention time enhances biological transformation in aerobic MBRs for 214 pharmaceuticals (Abegglen et al., 2009). It might also contribute to the transformation of PCMs in 215 this anaerobic system. It has also been shown that certain PPCPs are better removed under anaerobic conditions (e.g., antibiotics, naproxen, diatrizoate, estrogens and musk fragrances), while others are more effectively-treated aerobically (e.g. ibuprofen and bezafibrate) (Joss et al., 2004; Ternes et al., 2005). Redox conditions were found to be playing a very important role in PPCPs removal by Drewes et al. (Drewes et al., 2001), who investigated the removal of absorbable organo-iodine (AOI) in laboratory soil-column system under different redox condition. They found that the unsaturated aerobic conditions did not lead to significant biotransformation of AOI, saturated anoxic conditions produced about $20 \%$ removal, while the anaerobic conditions increased the removal to $57 \%$.

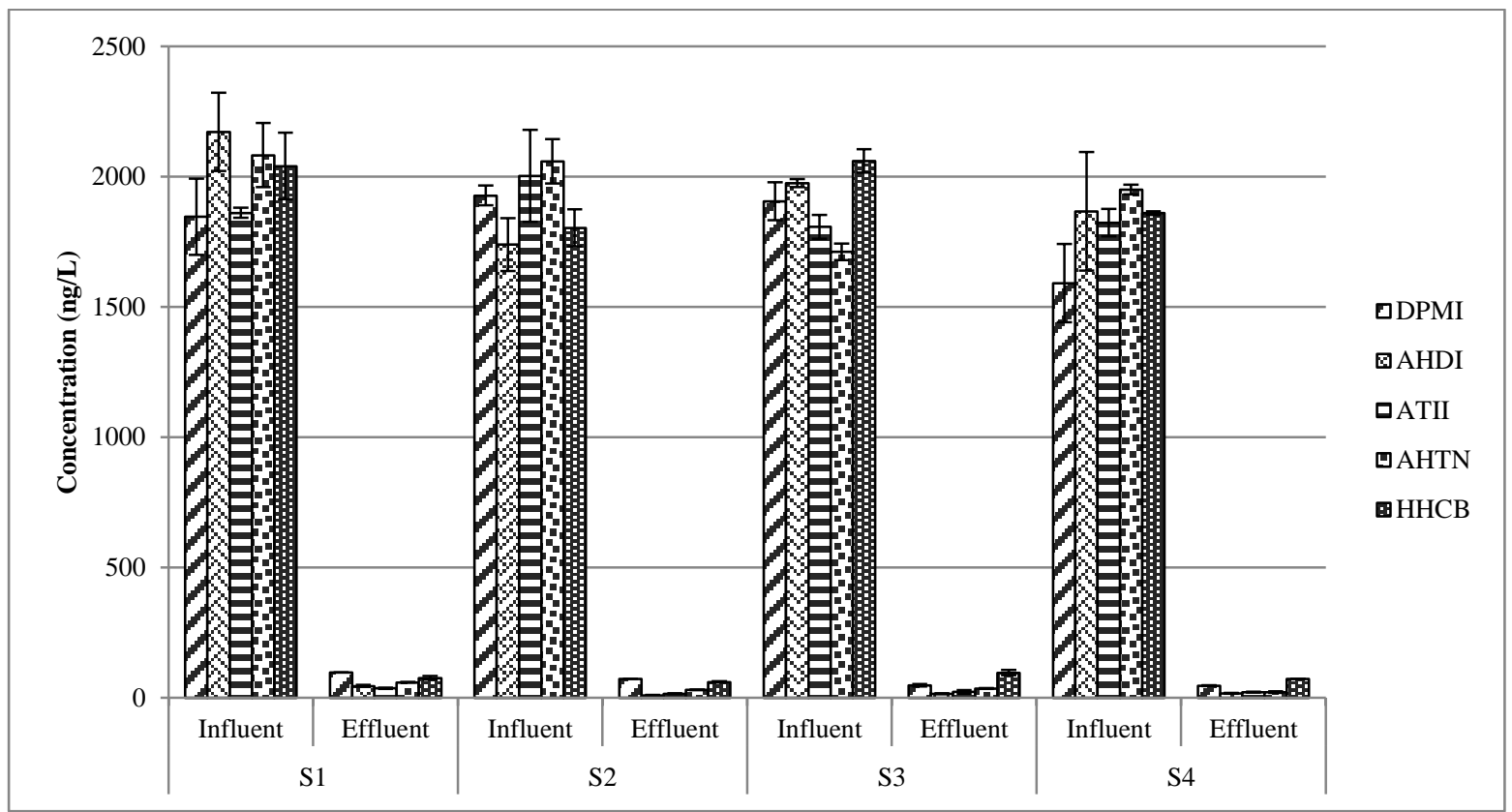

Figure 2: Concentration of individual PCMs in influent and effluent in the four sampling events (S1S4). Error bars represent the observed range of duplicate samples.

227 The concentrations of PCMs in dry biomass was calculated to be $44 \pm 13 \mathrm{ng} \mathrm{g}^{-1}$ (DPMI), $129 \pm 46 \mathrm{ng} \mathrm{g}^{-}$

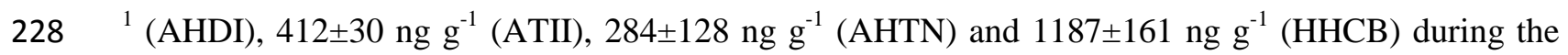
sampling period. Although some variation is evident from these figures, it is notable that no general increasing or decreasing trend was observed over the experimental period. This indicates that the PCMs were either being generally accumulated or released from the biomass during these experimental times. The mass balance of the PCMs in the AnMBR system is shown in Table 4. The removal of influent concentrations by biotransformation during the AnMBR process was $96 \%$ for DPMI, 97\% for AHDI, 94\% for ATII and 95\% for AHTN, respectively, while the removal of HHCB 
by biotransformation was somewhat lower $(83 \%)$. These biotransformation rates for AHTN under anaerobic conditions are somewhat greater than reported in a number of previous studies investigating full scale and pilot scale aerobic MBR (Joss et al., 2005; Ternes et al., 2005; Xue et al., 2010) and full scale conventional activated sludge (CAS) wastewater treatment (Kupper et al., 2006). There is no information regarding to the biotransformation rates of DPMI, AHDI and ATII in the open literature. Though sorption onto biosolids has been reported to contribute most to the removal of PCMs in aerobic systems, biotransformation is also non-negligible since transformation products including HHCB-lactone have been identified (Hühnerfuss et al., 2001; Kupper et al., 2004). Other authors have observed higher biotransformation for PCMs during aerobic MBR and CAS treatment. For example, Clara et al. (Clara et al., 2005) reported over 95\% removal of HHCB and AHTN by biotransformation in both CAS and MBR treatment.

The calculated average sorption coefficients $K_{d}$ for each of the PCMs are presented in Table 4. Highly variable $\mathrm{K}_{\mathrm{d}}$ values have been previously reported for PCMs in wastewater treatment reactors, with the differences possibly related to the type of reactor. For example, $K_{d}$ 's were determined to be $4920 \pm 2080 \mathrm{~L} \mathrm{~kg}^{-1}$ for HHCB and $5300 \pm 1900 \mathrm{~L} \mathrm{~kg}^{-1}$ for AHTN in primary sludge and $1810 \pm 530 \mathrm{~L}$ $\mathrm{kg}^{-1}$ for HHCB and $2400 \pm 960 \mathrm{~L} \mathrm{~kg}^{-1}$ for AHTN in secondary sludge (Ternes et al., 2004). However, values 2 to 3 orders of magnitude higher were estimated for HHCB $\left(10,040 \mathrm{~L} \mathrm{~kg}^{-1}\right)$ and AHTN $\left(15,400 \mathrm{~L} \mathrm{~kg}^{-1}\right)$ from activated sludge according to the published $\log \mathrm{K}_{\mathrm{ow}}$ values (Simonich et al., 2002).

Table 4: Mass balance and, biotransformation and sorption coefficients $K_{d}$

\begin{tabular}{|l|l|l|l|l|l|}
\hline & DPMI & AHDI & ATII & AHTN & HHCB \\
\hline Influent load $(\mu \mathrm{g})$ & 191 & 203 & 197 & 205 & 204 \\
\hline Effluent load $(\mu \mathrm{g})$ & 7 & 2 & 9 & 6 & 3 \\
\hline Biomass waste load $(\mu \mathrm{g})$ & 1 & 3 & 9 & 6 & 3 \\
\hline Biotransformation $(\mu \mathrm{g})$ & 183 & 198 & 185 & 195 & 169 \\
\hline $\begin{array}{l}\text { Removal by biomass } \\
\text { waste }(\%)\end{array}$ & 1 & 1 & 5 & 3 & 13 \\
\hline Removal in effluent $(\%)$ & 4 & 1 & 1 & 2 & 4 \\
\hline Biotransformation $(\%)$ & 96 & 97 & 94 & 95 & 83 \\
\hline $\mathrm{K}_{\mathrm{d}}\left(\mathrm{L} \mathrm{KgSS}^{-1}\right)$ & 749 & 7138 & 19242 & 16148 & 15560 \\
\hline
\end{tabular}

\subsection{Enantioselective fate of PCMs in AnMBR}

Enantioselective transformation of PCMs was investigated for the first time in this study. Designation, quantification and calculation of the enantiomeric composition of single enantiomers has been previously reported (Wang et al., 2013). The EF for each of the enantiomers of DPMI, AHDI, ATII, 
and AHTN was calculated as the relative fraction of the first eluted enantiomer and this was designated asEF1. For example, the EF1 for DPMI was calculated as EF1 = [DPMI1]/([DPMI1]+[DPMI2]). Since HHCB has four stereoisomers, full description of the stereoisomeric proportions requires the determination of the stereoisomeric fraction (SF) for three peaks (the fourth being implied). SF1, SF2 and SF3 were calculated as the relative fraction of the first, second and third eluted stereoisomer of $\mathrm{HHCB}$, respectively. Accordingly, these were determined as $\mathrm{SF} 1=$ [HHCB1]/([HHCB1]+[HHCB2]+[HHCB3]+[HHCB4]), $\mathrm{SF} 2=[\mathrm{HHCB} 2] /([\mathrm{HHCB} 1]+[\mathrm{HHCB} 2]+[\mathrm{HHCB} 3]+[\mathrm{HHCB} 4])$ $\mathrm{SF} 3=[\mathrm{HHCB} 3] /([\mathrm{HHCB} 1]+[\mathrm{HHCB} 2]+[\mathrm{HHCB} 3]+[\mathrm{HHCB} 4]) . \quad \mathrm{EF}$ analysis of these analytical standards at concentrations of $50 \mathrm{ng} \mathrm{mL}^{-1}$ and $500 \mathrm{ng} \mathrm{mL}^{-1}$ in ethyl acetate confirmed that $\mathrm{EF} 1$ was measured as 0.50 for DPMI, AHDI, ATII and AHTN, and SF1, SF2, SF3 and SF4 for HHCB were all measured as 0.25. Specific enantiomeric compositions of the first eluted enantiomer of DPMI, AHDI, ATII and AHTN in the influent were determined to have an EF1 $=0.50$ as racemic mixture. Most of them stayed as equal or nearly equal mixtures of enantiomers throughout the experiments and both in the biomass and effluent. No significant EF changes were detected for DPMI, AHDI, ATII and AHTN.

The elution order of the four stereoisomers ((4S, 7S)-HHCB, (4S, 7R)-HHCB, (4R, 7S)-HHCB, (4R, 7R)-HHCB) have been described in the literature (Biselli, 1999). The first eluted (4S, 7S)-HHCB and the fourth eluted (4R, 7R)-HHCB are the trans-enantiomer pair, and the second and third are the cisenantiomer pair. The first eluted two diastereomers of HHCB (4S configuration) are responsible for the significant musky odour. The average stereoisomeric compositions of the four stereoisomers of HHCB were all 0.25 in influent. Very minor SF changes were observed for HHCB in effluent and biomass, with average effluent SF values over the four sampling events being 0.27, 0.27, 0.25 and 0.21 for the four sequentially eluted stereoisomers and average biomass SF values being $0.27,0.27$, 0.24 , and 0.23 .This change can be observed by comparing the chromatographic peak sizes of the first and fourth eluted stereoisomers of HHCB in Figure 4. These results suggest that the third and fourth eluting stereoisomers of cis- and trans-HHCB may have been preferentially metabolised, leading to the small change in stereochemical composition.

There is only limited information about the enantioselective transformation and degradation of PCMs in the environment and during wastewater treatment (Franke et al., 1999; Gatermann, 1999; Hühnerfuss, 1999; Gatermann et al., 2002; Berset et al., 2004; Bester, 2005). However, each of these existing reports do suggest that there is potential minor enantioselective transformation of some PCMs under environmental and wastewater treatment conditions. 


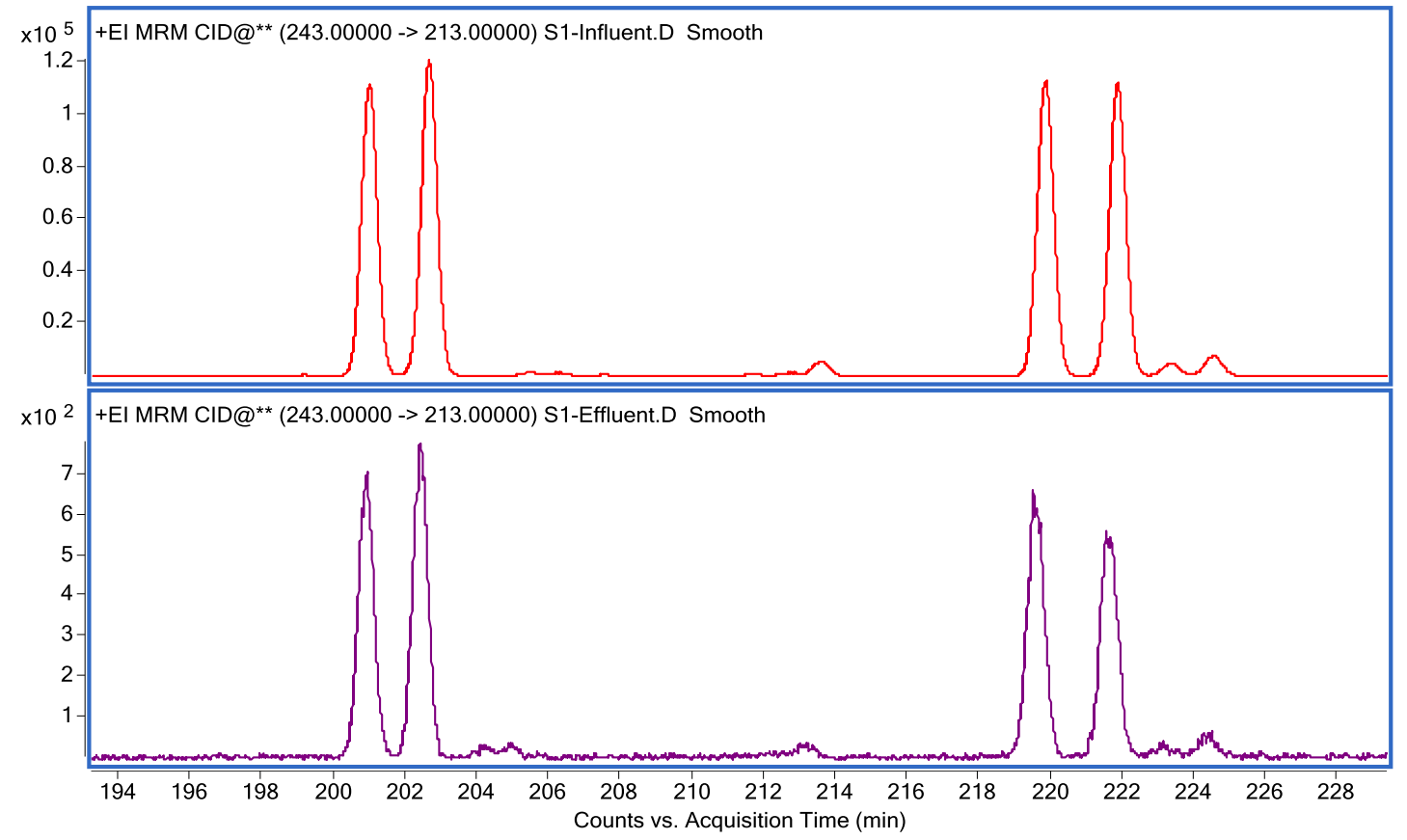

Figure 4: MRM chromatogram of HHCB in influent and effluent on the first sampling event

295

296

297

298

299

300

301

302

303

304

305

306

307

308

309

310

311

312

313

314

\section{Conclusion}

This study investigated the fate of five PCMs with a specific focus on individual stereoisomers of each PCM. Aqueous and biomass phases were both analysed to facilitate a full mass-balance for the removal of PCMs during AnMBR treatment. The AnMBR system showed high performance for elimination of PCMs from synthetic wastewater, with removal efficiencies of over $95 \%$ for all the analysed PCMs. Mass balance calculations indicate that biotransformation was the dominant removal pathway for PCMs by this AnMBR. Over 94\% of DPMI, AHDI, ATII and AHTN were removed through biotransformation and $83 \%$ for $\mathrm{HHCB}$. The sorption coefficients $\mathrm{K}_{\mathrm{d}}$ showed that these are hydrophobic compounds and significantly partitioned onto the biosolids phase in the anaerobic reactor. This strong partitioning to biomass is likely to have facilitated the observed biotransformational removal. Enantioselective analysis of these PCMs revealed negligible enantioselectivity for removal in most cases. Only very minor stereochemical compositional changes were observed for HHCB between influent and effluent samples. The results of this work indicate that AnMBR may be an effective treatment process for the removal of PCMs from wastewater and that all PCM stereoisomers can be expected to be removed with similar efficiency.

\section{Acknowledgements}

The authors thank China Scholarship Council for providing a PhD scholarship to Ms Lili Wang.

\section{References}

Abegglen, C., Joss, A., McArdell, C.S., Fink, G., Schlüsener, M.P., Ternes, T.A., Siegrist, H., 2009. The fate of selected micropollutants in a single-house MBR. Water Res. 43, 2036-2046. 
Alturki, A.A., Tadkaew, N., McDonald, J.A., Khan, S.J., Price, W.E., Nghiem, L.D., 2010. Combining $\mathrm{MBR}$ and NF/RO membrane filtration for the removal of trace organics in indirect potable water reuse applications. J. Membr. Sci. 365, 206-215.

Baek, S., Pagilla, K., Kim, H.-J., 2010. Lab-scale study of an anaerobic membrane bioreactor (AnMBR) for dilute municipal wastewater treatment. Biotechnol Bioproc E 15, 704-708.

Berset, J.D., Kupper, T., Etter, R., Tarradellas, J., 2004. Considerations about the enantioselective transformation of polycyclic musks in wastewater, treated wastewater and sewage sludge and analysis of their fate in a sequencing batch reactor plant. Chemosphere 57, 987-996.

Bester, K., 2005. Polycyclic musks in the Ruhr catchment area-transport, discharges of waste water, and transformations of HHCB, AHTN and HHCB-lactone. J. Environ. Monit. 7, 43-51.

Biselli, S.D., H.\& Gatermann, R.\& Kallenborn, R.\& König, W.A.\& Hühnerfuss, H., 1999. Separation of HHCB, AHTN, ATII, AHDI and DPMI by enantioselective capillary gas chromatography and preparative separation of HHCB and ATII by enantioselective HPLC. Organohalogen Compd. 40, 599-602.

Butler, R., MacCormick, T., 1996. Opportunities for decentralized treatment, sewer mining and effluent re-use. Desalination 106, 273-283.

Choo, K.-H., Lee, C.-H., 1998. Hydrodynamic behavior of anaerobic biosolids during crossflow filtration in the membrane anaerobic bioreactor. Water Res. 32, 3387-3397.

Clara, M., Gans, O., Windhofer, G., Krenn, U., Hartl, W., Braun, K., Scharf, S., Scheffknecht, C., 2011. Occurrence of polycyclic musks in wastewater and receiving water bodies and fate during wastewater treatment. Chemosphere 82, 1116-1123.

Clara, M., Strenn, B., Gans, O., Martinez, E., Kreuzinger, N., Kroiss, H., 2005. Removal of selected pharmaceuticals, fragrances and endocrine disrupting compounds in a membrane bioreactor and conventional wastewater treatment plants. Water Res. 39, 4797-4807.

Coleman, H.M., Troester, M., Khan, S.J., McDonald, J.A., Watkins, G., Stuetz, R.M., 2009. Assessment of trace organic chemical removal by a membrane bioreactor using gas chromatography/mass spectrometry and a yeast screen bioassay. Environ. Toxicol. Chem. 28, 2537-2545.

De Wever, H., Weiss, S., Reemtsma, T., Vereecken, J., Müller, J., Knepper, T., Rörden, O., Gonzalez, S., Barcelo, D., Dolores Hernando, M., 2007. Comparison of sulfonated and other micropollutants removal in membrane bioreactor and conventional wastewater treatment. Water Res. 41, 935-945.

Drewes, J.E., Fox, P., Jekel, M., 2001. Occurrence of iodinated x-ray contrast media in domestic effluents and their fate during indirect potable reuse. Journal of Environmental Science and Health, Part A 36, 1633-1645.

Eugene W. Rice, R.B.B., Andrew D. Eaton,Lenore S. Clesceri 2012. Standard Methods for the Examination of Water and Wastewater. American Public Health Association, Washington DC,USA.

Franke, S., Meyer, C., Heinzel, N., Gatermann, R., Hühnerfuss, H., Rimkus, G., König, W.A., Francke, W., 1999. Enantiomeric composition of the polycyclic musks HHCB and AHTN in different aquatic species. Chirality 11, 795-801.

Gatermann, R., Biselli, S., Hühnerfuss, H., Rimkus, G.G., Franke, S., Hecker, M., Kallenborn, R., Karbe, L., König, W.A., 2002. Synthetic Musks in the Environment. Part 2: Enantioselective Transformation of the Polycyclic Musk Fragrances HHCB, AHTN, AHDI, and ATII in Freshwater Fish. Archives of Environmental Contamination \& Toxicology 42, 447-453.

Gatermann, R., H. Hühnerfuss, S. Biselli, G. G. Rimkus, M. Hecker, R. Kallenborn, L. Karbe, 1999. Species-dependent enantioselective transformation of HHCB, AHTN and ATII in crucian carp (Carassius carassius) and tench (Tinca tinca). Organohalogen Compd. 40, 595-598. 
Hashim, N.H., Khan, S.J., 2011. Enantioselective analysis of ibuprofen, ketoprofen and naproxen in wastewater and environmental water samples. J. Chromatogr. A 1218, 4746-4754.

Hashim, N.H., Nghiem, L.D., Stuetz, R.M., Khan, S.J., 2011. Enantiospecific fate of ibuprofen, ketoprofen and naproxen in a laboratory-scale membrane bioreactor. Water Res. 45, 6249-6258.

Hühnerfuss, H., Biselli, S., Gatermann, R., Kallenborn, R., Rimkus, G.G., 2001. Enantioselective Analysis of the HHCB Metabolite HHCB-lactone in Environmental Samples. Organohalogen Compd. $52,441-445$.

Hühnerfuss, H.G., R.\& Biselli, S.\& Rimkus, G.G.\& Hecker, M.\& Kallenborn, R.\& Karbe, L, 1999. Enantioselective transformation of polycyclic musks in aquatic biota. Organohalogen Compd. 40, 401-404.

Ince, O., Babuna, F.G., Kasapgil, B., Anderson, G.K., 1998. Experimental Determination of the Inert Soluble COD Fraction of a Brewery Wastewater under Anaerobic Conditions. Environ. Technol. 19, 437-442.

Joss, A., Andersen, H., Ternes, T., Richle, P.R., Siegrist, H., 2004. Removal of Estrogens in Municipal Wastewater Treatment under Aerobic and Anaerobic Conditions: Consequences for Plant Optimization. Environ. Sci. Technol. 38, 3047-3055.

Joss, A., Keller, E., Alder, A.C., Göbel, A., McArdell, C.S., Ternes, T., Siegrist, H., 2005. Removal of pharmaceuticals and fragrances in biological wastewater treatment. Water Res. 39, 3139-3152.

Kupper, T., Berset, J.D., Etter-Holzer, R., Furrer, R., Tarradellas, J., 2004. Concentrations and specific loads of polycyclic musks in sewage sludge originating from a monitoring network in Switzerland. Chemosphere 54, 1111-1120.

Kupper, T., Plagellat, C., Brändli, R.C., de Alencastro, L.F., Grandjean, D., Tarradellas, J., 2006. Fate and removal of polycyclic musks, UV filters and biocides during wastewater treatment. Water Res. 40, 2603-2612.

Le-Minh, N., Coleman, H.M., Khan, S.J., van Luer, Y., Trang, T.T.T., Watkins, G., Stuetz, R.M., 2010a. The application of membrane bioreactors as decentralised systems for removal of endocrine disrupting chemicals and pharmaceuticals. Water Sci. Technol. 61, 1081-1088.

Le-Minh, N., Khan, S.J., Drewes, J.E., Stuetz, R.M., 2010b. Fate of antibiotics during municipal water recycling treatment processes. Water Res. 44, 4295-4323.

Lew, B., Tarre, S., Beliavski, M., Dosoretz, C., Green, M., 2009. Anaerobic membrane bioreactor (AnMBR) for domestic wastewater treatment. Desalination 243, 251-257.

Martinez-Sosa, D., Helmreich, B., Netter, T., Paris, S., Bischof, F., Horn, H., 2011. Anaerobic submerged membrane bioreactor (AnSMBR) for municipal wastewater treatment under mesophilic and psychrophilic temperature conditions. Bioresour. Technol. 102, 10377-10385.

Monsalvo, V.M., McDonald, J.A., Khan, S.J., Le-Clech, P., 2014. Removal of trace organics by anaerobic membrane bioreactors. Water Res. 49, 103-112.

Nghiem, L.D., Nguyen, T.T., Manassa, P., Fitzgerald, S.K., Dawson, M., Vierboom, S., 2014. Codigestion of sewage sludge and crude glycerol for on-demand biogas production. International Biodeterioration \& Biodegradation. (Accepted, DOI: 10.1016/j.ibiod.2014.04.023).

Nghiem, L.D., Tadkaew, N., Sivakumar, M., 2009. Removal of trace organic contaminants by submerged membrane bioreactors. Desalination 236, 127-134.

Radjenovic, J., Petrovic, M., Barceló, D., 2009. Fate and distribution of pharmaceuticals in wastewater and sewage sludge of the conventional activated sludge (CAS) and advanced membrane bioreactor (MBR) treatment. Water Res. 43, 831-841. 
Ricking, M., Schwarzbauer, J., Hellou, J., Svenson, A., Zitko, V., 2003. Polycyclic aromatic musk compounds in sewage treatment plant effluents of Canada and Sweden-first results. Mar. Pollut. Bull. 46, 410-417.

Rivera-Utrilla, J., Sánchez-Polo, M., Ferro-García, M.Á., Prados-Joya, G., Ocampo-Pérez, R., 2013. Pharmaceuticals as emerging contaminants and their removal from water. A review. Chemosphere 93, 1268-1287.

Saddoud, A., Ellouze, M., Dhouib, A., Sayadi, S., 2007. Anaerobic membrane bioreactor treatment of domestic wastewater in Tunisia. Desalination 207, 205-215.

Simonich, S.L., Federle, T.W., Eckhoff, W.S., Rottiers, A., Webb, S., Sabaliunas, D., de Wolf, W., 2002. Removal of Fragrance Materials during U.S. and European Wastewater Treatment. Environ. Sci. Technol. 36, 2839-2847.

Sipma, J., Osuna, B., Collado, N., Monclús, H., Ferrero, G., Comas, J., Rodriguez-Roda, I., 2010. Comparison of removal of pharmaceuticals in MBR and activated sludge systems. Desalination 250, 653-659.

Tadkaew, N., Hai, F.I., McDonald, J.A., Khan, S.J., Nghiem, L.D., 2011. Removal of trace organics by MBR treatment: The role of molecular properties. Water Res. 45, 2439-2451.

Tambosi, J.L., de Sena, R.F., Favier, M., Gebhardt, W., José, H.J., Schröder, H.F., Moreira, R.d.F.P.M., 2010. Removal of pharmaceutical compounds in membrane bioreactors (MBR) applying submerged membranes. Desalination 261, 148-156.

Ternes, T.A., Bonerz, M., Herrmann, N., Loffler, D., Keller, E., Lacida, B.B., Alder, A.C., 2005. Determination of pharmaceuticals, iodinated contrast media and musk fragrances in sludge by LC/tandem MS and GC/MS. Journal of chromatography. A 1067, 213-223.

Ternes, T.A., Herrmann, N., Bonerz, M., Knacker, T., Siegrist, H., Joss, A., 2004. A rapid method to measure the solid-water distribution coefficient (Kd) for pharmaceuticals and musk fragrances in sewage sludge. Water Res. 38, 4075-4084.

Trinh, T., van den Akker, B., Stuetz, R.M., Coleman, H.M., Le-Clech, P., Khan, S.J., 2012. Removal of trace organic chemical contaminants by a membrane bioreactor. Water Sci. Technol. 66, 1856-1863.

Visvanathan, C., Abeynayaka, A., 2012. Developments and future potentials of anaerobic membrane bioreactors (AnMBRs) Membrane Water Treatment 3, 1-23.

Wang, L., Khan, S.J., 2014. Enantioselective analysis and fate of polycyclic musks in a water recycling plant in Sydney (Australia). Water Sci. Technol. 69, 1996-2003.

Wang, L., McDonald, J.A., Khan, S.J., 2013. Enantiomeric analysis of polycyclic musks in water by chiral gas chromatography-tandem mass spectrometry. J. Chromatogr. A 1303, 66-75.

Wen, C., Huang, X., Qian, Y., 1999. Domestic wastewater treatment using an anaerobic bioreactor coupled with membrane filtration. Process Biochem. 35, 335-340.

Xie, M., Nghiem, L.D., Price, W.E., Elimelech, M., 2013. A Forward Osmosis-Membrane Distillation Hybrid Process for Direct Sewer Mining: System Performance and Limitations. Environ. Sci. Technol. 47, 13486-13493.

Xu, Y., Zhou, Y., Wang, D., Chen, S., Liu, J., Wang, Z., 2008. Occurrence and removal of organic micropollutants in the treatment of landfill leachate by combined anaerobic-membrane bioreactor technology. Journal of Environmental Sciences 20, 1281-1287.

Xue, W., Wu, C., Xiao, K., Huang, X., Zhou, H., Tsuno, H., Tanaka, H., 2010. Elimination and fate of selected micro-organic pollutants in a full-scale anaerobic/anoxic/aerobic process combined with membrane bioreactor for municipal wastewater reclamation. Water Res. 44, 5999-6010. 
Yang, J.-J., Metcalfe, C.D., 2006. Fate of synthetic musks in a domestic wastewater treatment plant 448 and in an agricultural field amended with biosolids. Sci. Total Environ. 363, 149-165. 